\title{
Nação, região, sertão e a invenção dos brasis: chaves de leitura para a história da educação
}

\author{
RUBIA-MAR NUNES PINTO \\ Universidade Federal de Goiás
}

Nas últimas décadas, a historiografia da educação brasileira tem dado a ver os estreitos vínculos entre a educação do povo brasileiro e os esforços dirigidos à construção da nação, ressaltando-se, em especial, o papel da escola na difusão e aprendizagem dos símbolos e heróis pátrios e na disciplina corporal e intelectual exigidas pela modernidade capitalista e industrial. Assim, ao encarar a escola sob o substrato da ideia de que as nações são invenções e constituem comunidades imaginadas (Anderson, 2008), o chamado nation building se tornou um horizonte sempre presente quando se pensa nas formas projetadas e implementadas para educar o povo do Brasil, retirá-lo da condição de suposta amorfia e forjar sua identidade. Os múltiplos enfoques e os distintos objetos de pesquisa tomados para compreender os elos históricos entre a escola e a construção do Brasil, contudo, não trataram ainda com a devida consistência do construto algo obscuro chamado região, o que faz com que a chamada questão regional se constitua um dos grandes desafios a serem enfrentados pelos historiadores da educação. Considerando a necessidade de atentar-se ao que vai sendo produzido num contexto de crescimento da produção do campo (Nunes, 2007), é preciso entender como os pesquisadores têm lidado com esta questão.

As pesquisas têm tratado a região, predominantemente, como critério para a delimitação espacial, referindo-se, quase sempre, às unidades federativas da República, mas podendo também indicar áreas mais reduzidas no seu interior (por exemplo, a região da Baixada Fluminense/RJ, do Triângulo Mineiro/MG etc.) 
ou ainda espaços urbanos, metropolitanos e rurais. Em inventários da produção historiográfica, como o realizado por José Gondra (2005), o regional identifica a dimensão político-administrativa (Norte, Sul, Sudeste, Nordeste e Centro-Oeste). Tratada desta forma, a região aparece como um dado que não requer posturas de estranhamento, tendo reduzido seu potencial explicativo das dinâmicas históricas que configuraram o campo da educação no Brasil. Tomando de empréstimo a reflexão de Carlo Ginzburg (1987, p. 29) sobre a noção de estranhamento, parece raro ainda, entre os historiadores da educação, o exercício de "compreender menos, [...] espantar-se" diante da região, exercício indispensável para ver aquilo que "costuma ser ocultado pelo hábito e pela convenção". Tal exercício, a bem da verdade, é também incomum na historiografia nacional e mesmo naquela compreendida como regional, conforme assegura Durval Albuquerque Jr. (2008, p. 1, grifos meus):

A região aparece como um dado prévio, como um recorte espacial naturalizado, a-histórico, como um referente identitário que existiria per si, ora como um recorte dado pela natureza, ora como um recorte político-administrativo, ora como um recorte cultural, mas que parece não ser fruto de um dado processo histórico. A bistória ocorreria na região, mas não existiria história da região. A bistória da região seria o que teria acontecido no interior de seus limites, não a bistória da constituição destes limites. A bistória regional seria aquela que aconteceria no interior das fronteiras regionais, não a história dos acontecimentos que produziram essas dadas fronteiras regionais.

Porém, como alerta Rosa Fátima de Souza (2007, p. 13), o crescente interesse pela história da educação nas regiões brasileiras externas ao eixo Sul-Sudeste - historicamente identificadas como centro ou nação - tem ofertado "novas possibilidades de análise, ressaltando especificidades ignoradas, dinâmicas singulares e dando visibilidade a outros atores sociais costumeiramente desconsiderados". Igualmente ressalta-se que a questão tem sido debatida, particularmente, em eventos regionais de história da educação, o que tem promovido importantes insights para que a região possa ser desnaturalizada e problematizada. Tais debates têm sinalizado para a região como unidade e posição de análise e como lugar epistemológico; não como realidade a ser estudada, mas "como o processo e o resultado de operações políticas, e porque não acadêmicas, que fundam a realidade e condicionam o modo de seu entendimento" (Faria Filho, 2007, p. 63). A região também é compreendida como lugar de trânsito de ideias educacionais e ações políticas (Cavalcante, 2007). Defende-se que o estudo da história da educação nas regiões implica a adoção de uma postura teórica e metodológica que se contraponha à narrativa uníssona e inequívoca da nação (Bastos, 2007). Quanto às possibilidades investigativas sobre o tema, Clarice Nunes (2007, p. 47) afirma que estudos comparativos entre processos de escolarização e urbanização em cidades de distintas regiões brasileiras podem "trazer à tona, com maior clareza, o processo contraditório de gestação do moderno, e captar [...] as aproximações e afastamentos entre os modos de fazer a educação [...] no Brasil". 
As sinalizações não são conflitantes e ajudam a pensar questões que permanecem em aberto: como ir além da identificação das singularidades regionais avançando para a percepção que - tal como ocorreu com a nação - as regiões brasileiras foram também inventadas e que, nestes processos, a educação dos sujeitos regionais foi objeto de atenção e disputas específicas decorrentes das condições reais e da história de cada uma das tantas partes do país? Como pesquisar as identidades e as diferenças, os ajustamentos e desalinhamentos entre nação e região e explicar a construção de uma unidade pedagógica e cultural a que nos referimos quando pensamos em educação brasileira? Qual o papel e significado da escolarização na definição das fronteiras e das identidades regionais? Que categorias teóricas, afinal, podemos operar para compreender os diálogos e os silêncios entre a nação e a região - ou entre centro e periferia - no surgimento e expansão da escola no país? Deve-se ter em mente que, no Brasil, a lógica centro/periferia permitiu que o centro se representasse como o nacional desenvolvido e civilizado, enquanto a periferia foi encarada como regional e representada como atrasada, selvagem e primitiva. Faz-se necessário, desta ótica, superar o enquadramento da região como mero recorte espacial ou administrativo, desnaturalizando-a, para encará-la como uma categoria que pode ofertar possibilidades para a interpretação histórica da educação nacional.

Para entender a região como invenção faz-se necessário, no caso brasileiro, pensar em quais respostas foram dadas à questão que, vencendo tempos e espaços, ainda ressoa entre nós: que país é esse? Depois da Independência e, particularmente depois de instaurada a República, a busca de respostas a tal questão se tornou algo urgente e inescapável. Afinal, para traçar rumos, definir projetos e participar da sociedade mundial era necessário construir uma nação e, diante do imenso desafio, foi preciso saber o que era o Brasil. Como se sabe, as respostas possíveis à questão tão complexa nunca estão ou estiveram dadas. Foi preciso forjá-las perscrutando tudo o que poderia conferir uma face à nação para, assim, definir sua identidade e tecer seu destino. Como também sabemos, inúmeros intelectuais brasileiros assumiram a tarefa de fazer a leitura do país, identificar seus pontos fortes, suas fragilidades, seu potencial e seus riscos, explicar o vasto território e a sociedade que o habitava para, enfim, propor caminhos e soluções. Deste investimento intelectual delinearam-se retratos do Brasil ${ }^{1}$ que, entre outras coisas, qualificaram sua diversidade regional. É, pois, no interior das tentativas de explicar o Brasil que se podem encontrar

1 Segundo Bolle $(2004$, p. 23-34), refere-se a conjunto de textos que explicam o país “[se aplicando] basicamente a ensaios de história e ciências sociais [...]. Os retratos do Brasil escritos no século XX estendem-se desde o livro fundador Os Sertões (1902), de Euclides da Cunha, até os últimos estudos de Darcy Ribeiro, passando pelas obras já clássicas de Gilberto Freyre, Sérgio Buarque de Holanda e Caio Prado Jr.[...] Raymundo Faoro, Celso Furtado, Antonio Candido [...]. [...] em meados da década de 1950, o romance de Guimarães Rosa [...]”. Estes autores são expressões do pensamento social brasileiro, conceito que agrega intelectuais que pensaram o Brasil e produziram interpretações e/ou estratégias políticas para a superação de problemas nacionais (Oliveira, 1998; Vidal e Souza, 1997). 
índices da construção de suas regiões. Assim, um dos possíveis para um adentrar compreensivo nas práticas e discursos orientados para a definição do regional e do nacional está na invenção discursiva da nação (White, 1994), a partir do qual é possível problematizar a região como construto teórico arduamente forjado por parcelas da intelectualidade brasileira na sua ânsia de entender e explicar o Brasil.

Voltando-se para tal invenção, este artigo trata inicialmente a interpretação do Brasil como uma nação dilacerada por uma dualidade que foi inscrita como elemento intrínseco de sua existência e que pode ser localizada no interior das preocupações com a unidade e indivisibilidade nacionais. Em seguida, a partir da tradição inventada (Hobsbawn; Ranger, 1984) que forjou a dualidade sertão-litoral, o texto apresenta as representações e imagens mais persistentes do sertão, ressaltando seu lugar marginal e periférico na construção da nação. Por fim, dou a ver aspectos da história da educação no estado de Goiás no período 1938-1942 como momento ímpar dos efeitos da interpretação dualística na construção de uma identidade regional. Mais precisamente, localizo os preparativos para a realização do VIII Congresso Brasileiro de Educação realizado pela Associação Brasileira de Educação (ABE), em 1942, em Goiânia, a então recém-edificada capital estadual. Naquele momento, a cidade foi constituída como um símbolo da modernidade sertaneja e da unidade nacional no coração da pátria geográfica: "cadinho onde se unem sertão e litoral” (Oeste, 1942, p. 3). No interior desta simbologia, foi significada como cidade-educadora e investida do papel de centro escolar de todo o sertão do oeste brasileiro. E se a educação dos brasileiros se colocava então como panaceia para os males que afligiam o corpo pátrio e como fundamento para a construção da nação, ela também foi pensada como dimensão essencial na invenção do "filho mais modesto, do filho menos educado" (idem, p. 18) entre os filhos do grande país-pai, ganhando centralidade com a realização do VIII Congresso Brasileiro de Educação em 1942.

A referência teórica privilegiada para uma brevíssima aproximação ao conjunto de narrativas da nação advém de estudos dedicados a compreender a construção da interpretação dualística do Brasil e os significados do sertão no pensamento social brasileiro (Amado, 1995; Lima, 1999; Sena, 2003, 2009; Vidal e Souza, 1997, 2002). Tais estudos refazem a trajetória dos sertôes imaginados, como ressalta Nísia Trindade Lima (1999), por certa elite intelectual brasileira que, ao olhar para o Brasil, identificou duas sociedades distintas convivendo no espaço nacional. Não é meu objetivo realizar uma abordagem pontual dos textos e autores que retratam o Brasil como nação dilacerada, mas tão somente sinalizar, em uma perspectiva generalizante, para as representações mais duradouras sobre esta dualidade e sobre como foi retratado seu polo negativo, a região-sertão. Assim, espero dispor elementos que ajudem a compreender os efeitos e impactos da invenção discursiva da nação na construção dos limites, da identidade e da cultura regionais e, a partir daí, encontrar chaves de interpretação possíveis para iniciar um processo de decifração do significado da região no surgimento, difusão e consolidação da escola entre nós ou, do seu reverso, do papel e lugar da educação e da escola na forja da região. 
A centralidade dos conceitos de nação, sertão e região neste artigo se relaciona menos com a tentativa de reavivar antigas querelas inter-regionais ou de trazer à luz explicações ultrapassadas sobre o Brasil, e mais com a perspectiva de contribuir para que o campo da história da educação possa refletir e pesquisar acerca da importante relação região-nação-sertão, da qual sobressai a interpretação do Brasil como uma nação cindida. Considerar esta tríplice e complexa relação, desta ótica, se mostra crucial para a compreensão do enraizamento da escola em nossa sociedade. As particularidades que a formação da nação assumiu notadamente nas primeiras cinco décadas do século XX e a força das formulações intelectuais e dos retratos do Brasil como uma nação dilacerada transformam a relação entre nação, sertão e região em algo essencial para pensar a escola que aqui surgiu e se consolidou. Como particular desafio - e convite - aos historiadores da educação brasileira permanece a tarefa de enfrentamento investigativo que contemple o que vejo como o núcleo duro da interpretação do Brasil como cisão: a permanência do sertão como um outro distanciado daquele que fala mesmo quando, ao se falar do chamado Brasil real, este outro apareça como nossa mais autêntica brasilidade e nosso manancial inesgotável de purismo. Lembro, então, Marcos Cézar de Freitas (2000, p. 58): “O Brasil permanece à espera de quem o conheça de perto”.

\section{A NAÇÃO UNA E INDIVISÍVEL E OS DOIS BRASIS}

Para compreender a história da educação na região é fundamental aceitar o desafio de lançar um olhar desconfiado sobre a narrativa hegemônica da nação (Bastos, 2007) para, assim, desconstruir uma leitura historiográfica que deixa a impressão de que o Brasil se fez de um só golpe. Trata-se de uma leitura ainda recorrente, nada neutra ou descompromissada, mas herdeira do processo que estabeleceu as bases para a nacionalidade sinalizando para as regularidades de um discurso implicado no modelo de nação e de Estado que se consolidou no Brasil e, portanto, na construção e no controle das representações, símbolos e mitos nacionais. Já no período imperial se constituiu a estrutura política e cultural na qual a região participava de modo secundário na construção da nação: o desenho de poder inaugurado com a Independência (1822) redefiniu, além do encaminhamento das lutas políticas do século XIX, um novo espaço geográfico no qual grande parte das regiões brasileiras ficou subordinada a um centro de poder formado por Rio de Janeiro, São Paulo e Minas Gerais (Mattos, 2004). A direção esboçada de uma centralidade política e cultural - e também econômica - em torno da qual a região se subordinava foi reafirmada na República (1889), o que consolidou a lógica centro/ periferia entre a nação e a região.

Daí surgiria a hierarquia de importâncias históricas $($ Revel, 1998) que delegou a região a um plano secundário na construção do país. Como se entre o nacional e o regional não existissem choques, rupturas e estranhamentos, mas apenas comunhão, integração e unidade, a região foi confundida com a nação, o que obscureceu a compreensão da sua invenção no interior do projeto de fazer o Brasil. Dito de outro 
modo, na construção do Brasil, a nação "prescindia [d]a ideia de região" (Sandes, 2001, p. 20), fazendo desta uma dimensão de somenos importância. A valoração da nação em detrimento da região pode ser compreendida como parte das preocupações com a unidade e indivisibilidade nacional que foram constantes durante $o$ Império. Ressaltar a diversidade regional significava minimizar a importância da nação una e indivisível e expor-se aos riscos e às possibilidades de sua fragmentação. Noé Sandes (idem, p. 18) comenta que a unidade nacional foi tomada pela historiografia brasileira "como a maior herança do Império. Associa-se à permanência das províncias unidas, sob o domínio do Império, o sentido da unidade nacional”.

A subordinação da região à nação pode ser identificada no interior das tentativas de explicar intelectualmente a nação, investimento que ganhou centralidade nas primeiras décadas da República quando uma expressiva parcela de intelectuais brasileiros voltou sua atenção para o mapa do Brasil e tomou o espaço como parâmetro para desenhar "regiões distintas que compõem a realidade nacional" (Sena, 2009 , p. 13). O espaço permitia enxergar a nação como um imenso, unificado e indivisível território. Rapidamente, o olhar que se lançava sobre a relação entre as porções do território (enumeradas e descritas) e os grupos sociais (qualificados em seus modos de agir, pensar e sentir) se dedicou a encontrar evidências históricas que confirmassem a existência da nação.

Naquele momento, alguns intelectuais - entre eles, Euclides da Cunha e Lima Barreto -, condenando a postura que só mirava para o estrangeiro, conclamavam a um giro sobre os calcanhares e a dirigir o olhar para dentro do mapa do Brasil. Ora, se havia algo dentro do mapa era porque, em algum momento do passado, o território fora conquistado e ocupado e exatamente aí se iniciava a história brasileira! A conquista e a ocupação do espaço pelos bandeirantes dos séculos XVI ao XVIII foram, então, colocadas no ponto zero da história, iniciando-se a contagem do tempo de existência nacional (Amado, 1995; Lima, 1999; Vidal e Souza, 1997). Mas, sem grandes preocupações metodológicas e interpretativas na reconstituição do passado histórico, "o sucesso das interpretações que falam da singularidade brasileira em termos de espaço é maior e mais duradouro do que o da retomada dos eventos históricos" (Oliveira, 1998, p. 1).

Da nação imaginada enquanto conquista e ocupação territorial, contudo, muito cedo sobreveio a percepção de uma descontinuidade seguida de um desconforto expresso exemplarmente na imagem euclidiana do intelectual desterrado em sua própria terra. Ao fixar o olhar dentro do mapa, viu-se que o imenso território era, de um lado, conhecido, povoado e iluminado por focos de civilização e ilhas de progresso e, de outro, repleto de vazios, desertos, sertões. A nação se revelou inconclusa e desequilibrada, separada por distâncias. Este contexto foi compreendido por aquela intelectualidade como uma dualidade que atravessava toda a realidade social brasileira. Mais, uma dualidade que era a própria representação da nação. Proliferaram as imagens de um país repartido: entre ricos e pobres, brancos e não brancos, bárbaros e civilizados, letrados e analfabetos, litorâneos e sertanejos. Em Os Sertões, Euclides da Cunha (1963) consagrou a ideia de que a heterogeneidade 
constitutiva do país era decorrente do afastamento geográfico e cultural entre sertão e litoral. A partir de então, o pensamento social brasileiro consolidou sertão e litoral como categorias que indicariam quais as áreas e sociedades pertenciam plenamente à nação e aquelas pensadas na condição de sua incompletude apenas como parte do ideal nacional. De acordo com Freitas (2000, p. 41), as narrativas sobre a nação foram evidenciando um descompasso entre o "[...] país que se conhecia e o país que deveria ser conhecido, ambos o mesmo Brasil". Partiram-se os lugares, separando-os a imensidão das distâncias. É nesta partição que se delineia a ideia da região como apêndice necessário - embora intrigante e um pouco assustador - da nação. Candice Vidal e Souza (1997, p. 36) afirma que

O olhar que narra, configurando os contornos internos do espaço-Brasil, confirma a diferença e conclui que a sociedade nacional não se horizontalizou por igual. [...] O diagnóstico uniforme nos textos conclui sobre a existência de uma porção desconhecida do Brasil. Certo de se estar em um mesmo país, resta descobrir se este outro lugar também compartilha do espaço nacionalizado [...].

A partição dualística do espaço nacional ensejou, assim, a partição social e cultural das regiões brasileiras. Segundo Vidal e Souza (idem, p. 39), as narrativas que explicam o país surpreendem pelos pontos de coincidência entre dois espaços geográficos identificados como sertão e litoral, sendo que "as clivagens políticas, sociais e econômicas [...] são inteligíveis, para os pensadores do Brasil, mediante esta bipartição geográfica e cultural do território nacional”.Já para Sena (2009, p. 1), "a imaginação social brasileira e nossa própria experiência de brasilidade tem-se construído, pelo menos desde o século XIX, em torno da imagem e do sentimento de que o Brasil é um país dual". Dualidade constantemente atualizada e recriada em muitas representações e imagens: sertão e litoral; capital e interior; civilização e barbárie; progresso e atraso; cidade e campo; urbano e rural; cópia e autêntico; moderno e tradicional; país legal e país real. A dualidade confluiu em uma cartografia imaginária do Brasil (idem; Vidal e Souza, 1997) que significou as distintas partes do território e os variados grupos sociais que nelas habitavam em termos de civilização e progresso em contraposição à barbárie e ao atraso, fazendo aparecer os contornos de um contraste implícito na relação sertão/litoral.

A ótica comparatória foi definindo traços e características de um e de outro, forjando classificações e hierarquias, constituindo o sertão como região e periferia, alteridade da nação (Sena, 2009), erigindo-se aqui um outro oriente (Freitas, 2000). Contudo, é necessário considerar, conforme afirma Lima (1999, p. 60), que

O dualismo sertão-litoral apresenta duas faces. Numa delas, o polo negativo é representado pelo sertão - identificado com a resistência ao moderno e à civilização. Na outra, o sinal se inverte: o litoral é apresentado como sinônimo de inautenticidade, enquanto antítese da nação. Em muitos autores, entre os quais a posição de Euclides da Cunha é exemplar, a ambivalência consiste na principal característica da representação que constroem sobre o país e seus contrastes. 
Ainda conforme a autora em tela, a valorização do litoral como sinônimo de inautenticidade levou os intelectuais brasileiros a sobrepor à dualidade sertão/litoral uma oposição entre uma civilização de copistas e uma cultura autêntica, porém, ainda a ser descoberta. Lima (idem, p. 62) comenta a respeito que "não por acaso, de Silvio Romero a Mário de Andrade, encontramos uma série de esforços de pesquisa das diversas manifestações artísticas disseminadas pelas regiões brasileiras”. Na verdade, conforme Sena (2009, p. 1), inúmeros foram os esforços empreendidos para entender como a "dualidade se constitui e propor, contra essa cesura, uma imagem unificada da nação, condição necessária da identidade nacional”. A grande tarefa a que se propôs a intelectualidade brasileira foi produzir um saber que contribuísse para alcançar a totalidade orgânica do país.

Neste sentido, é preciso considerar que a imagem de um Brasil cindido à espera da unificação impactou o campo da educação no Brasil ao longo do século XX. No cerne da luta pela democratização da escola para todos destacou-se a enorme responsabilidade regeneradora atribuída à educação para a superação dos atrasos e dos arcadismos brasileiros e, especificamente, para a reversão do desolador quadro da vida nos sertões. Os educadores, como parte ativa de uma intelectualidade comprometida com o progresso e a civilização, também elaboraram representações sobre o Brasil e o fizeram seguindo de perto as pistas de Euclides da Cunha. Conforme Freitas (2000, p. 42), entre os anos de 1920 e 1960, a trajetória intelectual dos educadores brasileiros vivenciou dois momentos de grande vigor intelectual, ambos sob a influência de Euclides da Cunha:

O primeiro momento foi o dos anos vinte e trinta, nos quais se interpelava o Estado a construir a obra educativa necessária à equiparação dos muitos brasis. Os ecos dos sertões na grita de Euclides da Cunha reverberam com força. [...] O segundo momento [...] ocorrerá na segunda metade da década de cinquenta, quando o Centro Brasileiro de Pesquisas Educacionais promoveu um novo mergulho no espelho de Euclides.

É instigante, pois, a tentativa de entender como os intelectuais-educadores se apropriaram da representação dual do Brasil, manejando-a em sua produção intelectual e em sua prática profissional. Também parece desafiador compreender como a imagem dos dois brasis afetou o campo da educação nas várias regiões brasileiras e se, entre outras coisas, haveria ressonâncias desta imagem nos sentidos constituídos para a escola em distintas sociedades regionais. Ao construir e difundir repertórios discursivos que se revelaram fortes o suficiente para caracterizar o território brasileiro e a gente que o ocupava, a imagem da cisão teria impactado o campo da educação no Brasil. Mas, através de que dispositivos e estratégias esta imagem alimentou discursos e fomentou práticas escolarizantes para as populações que viviam na imensidão do território?

Considerando a importância atribuída à escola na construção da pátria rica, unida e forte, os processos de escolarização seriam tributários das aspirações relacionadas à integração e unidade nacionais balizando, portanto, amplos processos 
de educação e aculturamento. Daí a importância de voltar-se para o regional na perspectiva de compreender se (e como) a imagem da unidade ou do dilaceramento da nação foi conformada nos projetos de educação das regiões brasileiras e se (e como) contribuiu para a construção do regional e, em particular, qual o lugar da escola nestes processos. Pode ser potencialmente promissor tentar entender de que forma os discursos e práticas formulados nos centros de poder foram apropriados pelas sociedades regionais, em particular, as mais afastadas. Ou seja, naquelas sociedades caracterizadas como sertão. Neste sentido, urge compreender o que é o sertão.

\section{SERTÕES IMAGINADOS}

O sertão é uma das mais poderosas representações construídas pela intelectualidade e cultura brasileiras em sua busca de respostas para a questão "o que é o Brasil?" "Entrelaçando imagens, ideias e emoções, o sertão se constitui como o suporte mítico, ageográfico e atemporal, da saga que narra a conquista da civilização pela nação brasileira em seu devir” (Sena, 2009, p. 1). Quase sempre pensado em uma ótica dualística que contém a virtualidade da inversão (Amado, 1995), a qual é mobilizada dependendo do lugar de onde se fala, o sertão se fez como instância da ambiguidade: inferno e paraíso; danação e salvação; doença e cura; causa da desintegração e sentido da unidade nacional; lugar de atraso e relicário de autenticidade; ônus econômico e maior reserva de riqueza. Conforme Sena (2009, p. 8-9),

[...] o sertão nunca foi um polo de uma bipartição apenas geográfica. Desde o tempo da colônia, o sertão é a alteridade concebida para se opor ao processo de civilização que o conquistador representa, entendendo-se em contraponto, o sertão como mais próximo da natureza. Como alteridade o sertão assombra a nação demonstrando o artifício da civilização brasileira, seu caráter postiço e inautêntico.

Desde a chegada dos portugueses, foi sinônimo de espaços amplos, desabitados e longínquos. Amado (1995) afirma que os portugueses já faziam uso da palavra desde o século XII para referir-se a áreas afastadas de Lisboa, mas situadas dentro do território português. A partir do século XV até o século XVIII, designou os domínios de Portugal na África, Ásia e América denominando espaços vastos, interiores, desconhecidos. No Brasil, a palavra preservou seu significado original, mas já no período colonial adquiria outro sentido que aquele dado pelos portugueses. Conforme Amado (idem, p. 148, grifos meus), o espaço sertanejo foi concebido então como "terras sem fé, lei ou rei, [...] de natureza ainda indomada, habitada por índios selvagens e animais bravios, sobre as quais as autoridades portuguesas [...], detinham pouca informação e controle insuficientes". O significado de sertão já se aproxima do conceito clássico de região: "relação entre centralização, uniformização administrativa e a diversidade espacial, física, cultural, econômica e política sobre a qual este poder central deve ser exercido" (Cunha, 2000, p. 42). 
No período imperial, a literatura romântica e os relatos naturalistas dos viajantes acrescentaram outros traços persistentes à imagem do sertão: a força da natureza, a relação simbiótica entre o homem e o meio, a quase impenetrabilidade, a degeneração racial dos nativos. Apesar do retrato em negativo, já se pode identificar também a ideia do sertão como espaço de autenticidade, em contraposição aos modelos de sociabilidade civilizados. Naquele momento, conforme Vidal e Souza (1997), o principal marcador de diferenças entre os dois brasis (Lambert, 1971) não era ainda o litoral, mas principalmente as distâncias entre o mundo sertanejo e os projetos modernizadores da Corte imperial.

Foi a chamada geração de 1870 - Tobias Barreto, Joaquim Nabuco, Silvio Romero, Graça Aranha, Euclides da Cunha, Capistrano de Abreu etc. - que fixou a ideia do sertão como polo oposto ao litoral. Os intelectuais desta geração compartilharam um tipo de nacionalismo que "[...] não se resumia em aplicar ao país as técnicas de conhecimento desenvolvidas na Europa” (Sevcenko, 2003, p. 96), mas em construir uma teoria sobre o Brasil como condição para uma intervenção lúcida e eficiente sobre seu destino. Nesta teoria, as distâncias foram acentuadas como a causa do atraso brasileiro. Não apenas as distâncias geográficas, mas igualmente as distâncias culturais e econômicas. A noção da distância permite enquadrar o olhar que explica nação de um ponto de observação determinado, o litoral. Portanto, distante era o sertão, realidade arcaica, território habitado por um povo inculto e avesso à civilização e que, pela sua extensão e situação de atraso, poderia ameaçar o processo civilizatório da nação.

Contudo, este lugar de ausência é revelado ao mesmo tempo como a essência da nação, como o Brasil profundo, o verdadeiro Brasil, o país não contaminado pelos estrangeirismos que se radicavam no litoral. Neste sentido, o legado de Euclides da Cunha é inegável, e sua influência, profunda e abrangente. O autor de Os Sertóes (1963) reforçava a imagem do sertão como território da barbárie, mantinha a atitude de negá-lo como parte do ideal nacional e localizava no atraso do mundo sertanejo os motivos do atraso da nação. Entretanto, em que pese o paradoxo, Euclides da Cunha optava pelo universo sertanejo como elemento de fundação da nacionalidade e reduto do homem primordial da brasilidade. Contraposto à civilização de copistas que se desenvolvia no litoral, na lavra de Euclides da Cunha o sertão conquistou uma grandiosidade épica que contrariava as teses raciais então vigentes: ali estava o locus original de uma raça brasileira autêntica e forte. O sertanejo não era um degenerado, mas um retardatário, o que explicava sua mentalidade e religiosidade atávicas e sua resistência à civilização.

O sertão estava, contudo, fadado a desaparecer conforme avançasse a onda civilizatória, pensava Euclides da Cunha. O tempo sertanejo seria acelerado, o sertão seria conhecido e dominado tornando-se plenamente Brasil e a nação alcançaria sua completude. Construto extremamente poderoso no pensamento social brasileiro, o desaparecimento do sertão pode ser identificado nas propostas e tentativas de instauração da modernidade e nos projetos de civilização de suas populações, inclusive, aqueles ligados à expansão da escolarização. 
Pensado no contexto da questão regional, o desaparecimento do sertão pela via da sua modernização colocou para as regiões sertanejas o imperativo de tornarem-se modernas ou, no limite, aproximarem-se dos signos e índices de modernidade das cidades do litoral e de suas adjacências como condição para o pertencimento à nação. Referido ao sertão, as expressões desaparecimento, civilização, incorporação e integração fizeram parte do mesmo campo semântico na medida em que sustentaram o sentido de conquista e ocupação do interior e de extensão da presença litorânea (civilizada) por todo o país, não se admitindo resistências nem do sertão - que não quer virar mar - nem do litoral - que resiste em aproximar-se do sertão (Vidal e Souza, 1997). O caráter colonizador dos projetos de integração e incorporação dos sertões foi posto pelo olhar que repete ad nauseum que o povo- massa (Oliveira Viana, 1999) que ali vivia era pouco brasileiro, já que não possuía consciência de deveres e direitos de cidadania, mostrava-se preso ao cotidiano local e pouco disposto a contribuir para a construção da nação e do Estado nacional.

A incorporação do sertão à nação requeria, portanto, a educação do povo sertanejo em direção à consciência política entendida, principalmente, como aceitação e submissão ao Estado. Daí a importância da educação no projeto de civilização do sertão. Euclides da Cunha (1984, p. 87-88, grifos meus) escreveu que a destruição de Canudos pelas forças militares republicanas representava ato de conhecimento e transformação dos sertões e um sinal de alerta aos governantes da nação sobre "o abatimento intelectual em que jazem os que as habitam. [...] este [...] um inimigo permanente". Para vencer este inimigo, Euclides da Cunha (idem, p. 89) anteviu a civilização do sertão por meio da educação de suas populações:

Que pelas estradas, ora abertas à passagem dos batalhões gloriosos, que por essas estradas amanhã silenciosas e desertas, siga, depois da luta, modestamente, um herói anônimo sem triunfos ruidosos, mas que será no caso vertente, o verdadeiro vencedor: o mestre-escola.

A herança de Euclides da Cunha impactou significativamente nas primeiras décadas do século XX, inspirando, entre outras coisas, a luta dos intelectuais-educadores pela escola pública e incentivando a ida aos sertões. Lima (1999) lembra que foi intenso o movimento de cientistas brasileiros rumo ao interior nas décadas de 1910 e 1920. Seguindo as pistas do autor de Os Sertôes, era urgente que os homens da ciência conhecessem o outro Brasil e que se pusessem a serviço de sua incorporação e integração, vale dizer, do seu processo civilizatório. Não foi outra a intencionalidade dos cientistas da Fundação Oswaldo Cruz na década de 1910 quando desencadearam a Campanha pelo Saneamento dos Sertões e, em suas viagens científicas, se viram diante de um sertanejo pobre, deseducado e doente e, por isso, atavicamente preguiçoso, modorrento, quase inerte. Mas, representado como patologia e abandono, o sertão manteve-se como espaço da autenticidade e da essência da vida nacional (idem).

Porém, se em Euclides da Cunha eram a mentalidade e religiosidade mestiças que faziam com que o sertanejo resistisse à mudança e ao fatalismo de um processo 
civilizatório visto como inevitável, para os intelectuais das décadas de 1910 e 1920 o problema estava na inexistente ilustração e na proliferação incontrolada de moléstias, ambas provocadas pelo abandono em que viviam as populações sertanejas. Entregue às broncas oligarquias regionais, o interior brasileiro mostrava a face de um Brasil doente, deixando evidente que a República não cumprira sua promessa civilizatória. A imagem da doença que ia sendo agregada ao universo sertanejo produzia deslocamentos nas representações sobre o sertão e seus habitantes, confrontando a grandiosidade épica do sertanejo euclidiano com a imagem de um ser cheio de verminoses e doenças provocadas pelo clima tropical e mantidas pela ignorância, pela superstição e pelo abandono do Estado. A região-sertão se tornava também o lugar da doença e do abandono, mas mantinha-se como lugar da essência da brasilidade. Assim, o sertão era confirmado como um estranho perigoso, mas um estranho promissor desde que conhecido e domesticado. Uma ameaça que era preciso fazer desaparecer para que o país - finalmente civilizado, finalmente integrado - se constituísse nação.

A grita euclidiana pela incorporação dos sertões finalmente ganhou fôlego durante a Era Vargas (1930-1945), momento em que assumiu a face de uma política pública, a Marcha para o Oeste (1938). A partir dos anos de 1930, o caminho para os sertões do oeste - visto como alternativa viável e inteligente para o Brasil desde os tempos imperiais - apareceu como inevitável dado suas propagadas potencialidades econômicas. Compreendido na longa duração e inserido nas narrativas sobre o Brasil, o caminho para os sertões do oeste vem se constituindo como um amplo projeto de integração e modernização da nação e revelado uma das faces mais agressivas da ação do Estado nacional em direção ao desaparecimento do universo sertanejo. Pensado no contexto da euforia nacionalista da Era Vargas, a marcha para os sertões do oeste ganhou o sentido épico da nação que caminhava para dentro de si mesmo, na direção do seu coração, em busca da sua verdadeira identidade. Marcha para o Oeste é também título do livro de Cassiano Ricardo (1940), no qual se reforça a interpretação dualística do Brasil como também uma concepção geográfica da pátria. Desta ótica, nacionalizar o espaço da nação, ou melhor, abrasileirar o sertão apareceu como fórmula para a conquista de um país autêntico, progressista e moderno. É este o momento em que, conforme Sena (2009, p. 12, grifos do original), o pensamento social brasileiro enxerga o sertão como "fronteira por excelência vinculando-o à pátria geográfica como possibilidade de expansão da nação através da incorporação econômica e ocupação de terras [...]".

$\mathrm{Na}$ medida em que abrasileirar o sertão foi compreendido como instaurar a modernidade no interior do território, tornar-se moderno apareceu como condição de superação do estigma de periferia da nação. Em função desta compreensão, o sertão vem passando por dinâmicas de empurramento que o dotam de extraordinária mobilidade no território nacional e fazem dele "a memória de um tempo passado e de um constrangimento" (idem, p. 4). São Paulo é exemplo emblemático desta dinâmica. Tendo algumas de suas partes pensadas com o sertão até o início do século XIX, São Paulo baniu esta representação substituindo-a pela representação do estado 
locomotiva. Já Minas Gerais trilha o caminho contrário operando o desaparecimento dos seus sertões por meio do seu "englobamento [...] pela representação Minas Gerais, estilhaçando os gerais do Grande Sertão: veredas, sob as imagens das montanhas e do ouro" (idem, ibidem). No século XXI, o sertão mostra-se ainda móvel: o estado de Goiás tem tentado - sem sucesso - deslizar os signos sertanejos agregados à região através do seu confinamento ao Tocantins, antigo norte estadual. Em contrapartida, vencer os signos sertanejos por meio da urbanização foi também um dos caminhos trilhados para modernizar o sertão e integrar Goiás à nação. Cidades planejadas e construídas, em particular, foram vistas como dispositivos capazes de transpor distâncias e gerar aproximações que instaurassem a modernidade e assegurassem a plena integração do regional ao nacional.

Um acontecimento de enorme significado para a invenção de Goiás como região moderna e integrada à nação foi o surgimento de Goiânia (1937), cidade-capital regional significada como símbolo de modernidade no sertão goiano e sinal inequívoco da pátria unida e integrada em torno do ideal nacional. Em 1942, na inauguração oficial da nova capital de Goiás, uma reunião nacional de educadores se constituiu dispositivo singular para difundir a simbologia de unidade nacional e momento de grande importância para que Goiás se apresentasse sob os signos da modernidade, o que equivale a dizer como parte da nação. $O$ olhar lançado sobre este acontecimento pretende demonstrar como uma discursividade, que ao construir e fixar a imagem dos dois brasis, pode ter impactado na conformação do campo da educação das regiões. Por isso, atentar-se para a história da educação de sociedades periféricas tais como a goiana se revela fundamental para aprofundarmos o conhecimento sobre como a escola foi se enraizando nas diferentes experiências históricas das variadas espacialidades onde a escolarização foi se expandindo e a nação se fazendo pelos amplos espaços de um país, desde cedo, pensado como cisão.

\section{CELEBRAR A PÁTRIA ÚNICA, INTEGRAR NAÇÃO E REGIÃO: RITUALÍSTICA E SIMBOLOGIA DO VIII CONGRESSO BRASILEIRO DE EDUCAÇÃO (1942) EM GOIÂNIA/GO}

É impossível deixar de perceber os impactos e efeitos da interpretação dualística do Brasil e do projeto de incorporação do sertão no estado de Goiás, região periférica, considerada inóspita e incivilizada; assujeitada pela hierarquia de importâncias históricas na história nacional (Revel, 1998). Após a década de 1930, o estado de Goiás foi alvo privilegiado de políticas de integração e unidade nacionais tais como a Marcha para o Oeste (1938) e o Plano de Metas JK (1955). Os sentidos da unidade e integração nacional estiveram também presentes na divisão territorial que criou o estado do Tocantins (1988). No termo desta movimentação, havia um novo mapa geopolítico da nação e três cidades-capitais - Goiânia (1937), Brasília (1960) e Palmas (1990) - projetadas e construídas nos sertões dos goyases como modelos de modernidade e promessas do novo Goiás e do novo Brasil. O aparecimento destes núcleos urbanos implicou em uma radical redefinição territorial do 
estado que configurou duas novas identidades regionais: além dos goianos, vivem no antigo estado de Goiás, brasilienses e tocantinenses.

Ponto de partida histórico deste processo, a construção de Goiânia ensejou oportunidades ímpares para os ideais de superação da condição sertaneja de Goiás. Planejada e construída segundo os parâmetros de um plano urbanístico racional e da então moderna arquitetura art déco e inaugurada em plena vigência do Estado Novo - "sua filha mais dileta"(Oeste, 1942, p. 2), sua "flor miraculosa" (idem, p. 3) -, Goiânia foi simbolicamente constituída como cidade moderna e como promessa de uma nova história regional, mas igualmente como ícone de uma nação que bania o seu sertão.

Assumindo a perspectiva de Jacques Le Goff (2003, p. 208), é possível inferir que, com a edificação da sua nova cidade-capital, os goianos procuravam “[...] reagir perante seu passado [de desconhecimento, isolamento, não pertencimento, decadência e atraso]" e projetar, para si, outro futuro. Goiânia era a demonstração inconteste do valor operatório do povo sertanejo e da sua capacidade de forjar a própria história e, por isso, Goiás merecia ser reconhecido e respeitado como região de grande importância para o futuro da nação, diziam os discursos que constituíam os sentidos da cidade. Finalmente era "sohada a grande hora de Goiás" (Correio Oficial do Estado de Goiaz, 1942, p. 1). Comemorou-se o arrojo de seus políticos, sua economia e a projeção de seus intelectuais e políticos:

Jamais foi tão sólida e tão brilhante a posição de Goiás no cenário da vida nacional. [...] Os jornais e as revistas da Capital Federal e de todo o país trazem, diariamente, noticiário farto sobre as possibilidades do nosso Estado e as realizações do nosso govêrno. [...] Representantes de Goiás em congressos efetuados na Capital Federal são distinguidos de modo especial pelas altas autoridades da República [...]. [...] Nossos jornalistas vêm seus artigos transcritos e elogiados nas folhas dos Estados irmãos e até em livros. Nossos escritores vencem concursos literários. (Oeste, 1944, p. 15)

A ideia da construção de uma nação moderna mobilizava mentes e corações, catalisando as projeções de um grande futuro para o país. O momento apresentava-se pleno de oportunidades para consolidar a simbologia de um Brasil que marchava para seu coração, lugar do autenticamente nacional. Neste sentido, a instauração do Estado Novo em 1937 foi instrumento que permitiu e estimulou a invenção de Goiás no século XX na medida em que oportunizou o reforço e espraiamento da simbologia da cidade-capital moderna e lugar da unidade da nação dilacerada em sertão e litoral. O Estado nacional, finalmente, voltou seus olhos para Goiás e para o celebrado significado moral, cívico e econômico de Goiânia através da Marcha para o Oeste, política de promoção do desenvolvimento econômico das regiões campesinas do centro do Brasil que visava integrá-las à nação por meio do incremento produtivo da terra. A integração produtiva dos sertões do oeste trazia, por sua vez, a necessidade de educar suas populações para a vida e o trabalho rural e a conformação de novas mentalidades e comportamentos para o povo sertanejo (Prado, 1995). 
Foi neste contexto que ocorreu a inauguração oficial da nova capital goiana no evento ritual denominado Batismo Cultural de Goiânia (1942), o qual é tributário dos sentidos que se constituíam para a cidade. Conforme Ferreira (1986, p. 192), batismo significa "ato que nomeia uma pessoa ou coisa, admissão solene a uma seita religiosa, um renascimento espiritual com purificação de todas as culpas e pecados". Inserido na simbologia de Goiânia, remete à ideia de um renascimento da região dos goyases, à expiação dos pecados de seu próprio passado e a sua admissão nos circuitos de poder da nação. Se pensada no contexto da busca de unidade para a pátria dilacerada, remete ao desejo de significar a cidade-capital de Goiás como momento e lugar de um renascimento do Brasil. Ao ser apresentada à nação em um ritual denominado batismo, Goiânia adquiria o sentido de um renascer tanto para a desconhecida região da qual se tornava centro quanto para a imensidade da nação da qual era, espacialmente, o ponto nuclear. A festa adquiriu um caráter de integração nacional e de comunhão do sentimento nacionalista (Vidal e Souza, 2002).

O principal acontecimento do Batismo Cultural, e também parte das solenidades do lançamento oficial da Marcha para o Oeste, foi o VIII Congresso Brasileiro de Educação da ABE. A Marcha, programa-síntese de um projeto de nação compartilhado também por grande parte dos intelectuais-educadores brasileiros, foi desencadeada pelo governo federal em 1938. Entretanto, quatro anos depois foi oficialmente lançada em Goiânia por ocasião da sua inauguração. Por sua vez, a cidade-capital goiana já era uma cidade entregue ao estado de Goiás, cumprindo plenamente seu papel de centro do mundo regional desde 1937. Isto é, Goiânia e a Marcha já estavam inauguradas, fazendo com que o Batismo fosse teatralizado e a celebração se fizesse como encenação da imagem da nação unificada. Se interpretado como discurso que dizia da vinculação entre a nação e a região, nada poderia ser mais representativo. De outro lado, a centralidade do Congresso na inauguração oficial de Goiânia tornou a educação a grande estrela do acontecimento que reunia os anseios e expectativas regionais e nacionais em fazer do Brasil grande um grande Brasil.

Discutindo o ensino rural - seu tema principal -, o Congresso da ABE pode ser compreendido como sinal do entusiasmo e da adesão dos meios educacionais e intelectuais e do Estado brasileiros ao surgimento de Goiânia e sua promessa civilizatória e integradora. Desta ótica, instituiu-se um duplo movimento cujo eixo de articulação era a questão educacional: de um lado, por meio do Estado nacional, de seus intelectuais e educadores e em função do projeto de poder que estava em curso, a nação reconhecia e valorizava a nova capital estadual, tirando proveito da iniciativa das elites e do Estado goianos na construção da cidade e aderindo aos sentidos de modernidade e pertencimento para ela constituídos. De outro, as elites intelectuais e políticas regionais igualmente aproveitavam as brechas que o regime estadonovista deixava abertas para fazer do Congresso um dos principais meios de divulgação da imagem de cidade moderna e educadora e, assim, expandir e reforçar a simbologia de modernidade e pertencimento à nação da jovem capital goiana. No texto introdutório dos Anais do VIII Congresso da ABE (1944, p. 9), José Augusto 
Bezerra de Medeiros, Fernando Tude de Souza e Mario Augusto Teixeira de Freitas formularam um discurso que sinaliza para a apropriação e enriquecimento da discursividade que constituía os sentidos de Goiânia:

[...] quase no centro de nosso quadro geográfico, em contato com a ambiência mais caracteristicamente brasileira que se poderia desejar, confirmou-se uma nova e moderna metrópole na sua magnífica destinação política, social, econômica e cultural: a de se constituir efetivamente o marco inicial e, ao mesmo tempo o ponto de apoio da nova política do Brasil - aquela política que há de integrá-lo, erguê-lo, torná-lo invulnerável em sua grandeza.

Desde 1938, a ideia da realização de um congresso da ABE em uma cerimônia de inauguração oficial da cidade era veiculada em Goiânia. Em 5 de fevereiro de 1939, o jornal O Popular (p. 1, grifos do original) publicou discurso de Mario Augusto Teixeira de Freitas na cerimônia em que entregara a presidência da ABE a Fernando de Azevedo (em dezembro de 1938) em que este afirma que o interventor goiano tomara a iniciativa de sediar o congresso na nova cidade-capital de Goiás:

Este certame pelo que deliberara o congresso de 1935, tendo em vista a proposta da delegação paraense, deveria realizar-se em Belém. Mas as dificuldades financeiras com que tem lutado o estado do Pará, levou o seu governo, depois de demorada resolução, a desistir da preferência que lhe estava assegurada. E como o governo do estado de Goiás nos tivesse manifestado o desejo de que o referido congresso se realizasse em Goiânia constituindo o batismo cultural da nova capital do estado, ao ter logar o ato de sua inauguração oficial em junho de 1939, compromissos definitivos foram assentados entre a presidência da $\mathrm{ABE}$ e s. exma. o Interventor Pedro Ludovico.

É exatamente a partir de 1939 que o governo estadual iniciou cortes no orçamento, redirecionando verbas para a nova cidade-capital. Em discurso pronunciado nas solenidades de abertura do Congresso em 1942, o interventor Pedro Ludovico Teixeira (1973, p. 162) explicou que a ABE abriu mão da data inicialmente combinada para a realização do Congresso e esperou que Goiânia pudesse sediá-lo, como também o fez o governo federal:

Há dois anos atrás, já devia ter-se reunido em Goiânia este Congresso [...]. Não se objetivou naquela época $[. .$.$] em virtude [\mathrm{dos}]$ percalços que surgiriam para uma cidade muito nova em receber componentes de tão distinto e refinado conclave. Não concordou [Mário Augusto Teixeira de Freitas] com o cancelamento da resolução tomada. Adiou-a, até que se pudesse realizar [...]. Ficou decidido que seria nessa Capital a sede do Oitavo Congresso Brasileiro de Educação.

Prado (1995,p. 11) afirma que o Congresso de 1942 “[...] teve caráter emblemático, pois [...] representou de maneira muito expressiva o panorama de discussões travadas naquele momento acerca das questões educacionais", constituindo-se, 
juntamente com a Marcha para o Oeste, acontecimentos especialmente importantes para o entendimento do ruralismo pedagógico como discurso estadonovista sobre a educação dos brasileiros. A localização geográfica da cidade sede foi decisiva para difundir uma simbologia de unidade e integração nacional. Conforme a autora (idem, ibidem), "o fato de a cidade de Goiânia encontrar-se no centro do Brasil foi explorado em seu simbolismo. Em torno dele construiu-se a ideia de integração nacional e de expansão e de conquista de regiões brasileiras até então praticamente inexploradas". Na ideologia do Estado Novo "a chegada em uma terra selvagem e despovoada deveria ceder lugar a um baluarte da ocupação civilizadora do interior, uma capital tornada símbolo da integração nacional (Camargo, 2001, p. 124).

Para a elite letrada de Goiás, o interesse do Estado nacional e das elites esclarecidas do país pela nova capital estadual assumiu o significado da aceitação e do reconhecimento que balizaram a construção discursiva de Goiânia. "Longos e ásperos foram os anos de luta. [...] sem par foi a abnegação e superlativas a coragem e a energia”, escreveu Vasco dos Reis, Diretor de Educação de Goiás (Correio Oficial do Estado de Goiaz, 1942, p. 1), às vésperas do Congresso. E continuando: "[...] a vitória vem raiando com esplendores tantos [...]. Venha a nós essa plêiade brilhante de espíritos cheios de saber [...]”. Era como se a cidade-capital goiana finalmente cumprisse a promessa que sustentou seu surgimento: a projeção de Goiás no cenário nacional e a promoção de sua entrada triunfante na história da nação, abrindo-lhes as portas do pertencimento e da relevância. Nos anos de luta em que Goiânia se preparava para o momento glorioso em que o coração da nação se faria o centro do mundo educacional brasileiro, as novidades inundaram o campo da educação goianiense, enriquecendo a imagem de cidade-educadora e centro escolar dos sertões do oeste. O governo estadual lançou-se efetivamente ao trabalho de construir as condições para a realização do Congresso da ABE.

A política educacional desencadeada após a transferência da capital (março/1937) mantinha as premissas da modernização da escola goiana - já presentes, na realidade, na legislação desde os anos de 1910 - e a adesão às diretrizes emanadas do recém-criado Ministério da Educação e Saúde. Entretanto, é possível interpretar que tal política visava ainda dois outros objetivos: primeiro, forjar uma cultura urbana em íntima associação com a cultura escolar, tal como ocorriam nas modernas e civilizadas cidades do litoral. E, em segundo lugar, as ações e iniciativas do governo estadual preparavam o terreno para a realização do Congresso da ABE. Tratava-se de colocar em andamento uma rápida organização educacional para que a cidade-capital pudesse suportar os olhares de toda a nação. O discurso do técnico educacional Gentil Augusto Lino, em "Reorganizemos" (Correio Oficial do Estado de Goiaz, 1938, p. 3), parece fornecer a tônica do esforço do governo estadual:

Idealizando e agindo rapidamente, si bem que o problema não é de correr, mas de chegar depressa, empurremos, com sofreguidão, o carro do nosso progresso educacional. [...]. Trabalhemos mais que falemos; sejamos práticos e perspicazes nas idéias e nas realizações. 
Entre as ações do governo estadual, ganha ênfase a promoção de dois congressos regionais de educação primária (1937 e 1938), a publicação da Revista de Educação do Estado de Goiás (1938) e a realização de concursos para seleção e admissão de professores para as escolas goianienses (1938). No período 1938/1940 foram também inaugurados os prédios do Grupo Escolar Modelo e do Liceu de Goiânia. Por meio destas iniciativas, parece-me que o Estado tentava criar as condições materiais, culturais, pedagógicas e intelectuais mínimas para que a cidade recebesse o VIII Congresso Brasileiro de Educação. Os congressos estaduais e a publicação da revista pedagógica atuaram como estímulo para que o professorado primário goiano desenvolvesse experiências educacionais consideradas modernas e pudesse, assim, adentrar na seara da autoria. Um recorrente convite à autoria pode ser encontrado nas páginas da Revista de Educação. No editorial de seu terceiro número (idem, p. 37, grifos meus), Vasco dos Reis dirigiu um instigante apelo aos professores goianos ao afirmar que a finalidade maior da Revista era oferecer:

[...] um campo fértil ao vasto talento creador dos professores goianos e dos afeiçoados da pedagogia. A esse elemento de que dispomos está confiada $a$ tarefa ingente de imprimir um sentido goiano às novas aquisições científicas no terreno educacional, adicionando contingente próprio ao que já é do domínio geral.

Do discurso emana a ideia de que a revista tinha como uma de suas finalidades qualificar o professorado goiano nos ditames da modernidade pedagógica e, assim, prepará-lo para a autoria. A partir do início de 1942, Vasco dos Reis ocuparia a imprensa local dirigindo convites expressos para a participação no Congresso de Educação. Em 15 de fevereiro de 1942, o Correio Oficial do Estado de Goiaz (p. 1, grifos meus) publicou um destes convites em sua primeira página:

Empenhada em que maior brilhantismo tenham as reuniões do $8^{\circ}$ Congresso Nacional de Educação [...], a Diretoria de Educação por esse meio vem convidar a todos quantos possuam experiência e conbecimento necessários em assuntos educacionais a que procurem cooperar no certame. Essa cooperação poderá efetivar-se por meio de teses [...] que devem ser defendidas pelos interessados.

É preciso ainda considerar os professores aos quais era dirigido o apelo. Quem eram aqueles que possuíam experiência e "conhecimento necessários em assuntos educacionais"? Esta questão me leva aos processos de seleção de pessoal docente do período. Nos primeiros meses de 1938, a realização de concursos públicos para preenchimento de vagas nas escolas públicas goianienses animou a cena urbana da cidade-capital. A imprensa local divulgou amplamente os concursos e celebrou os aprovados louvando sua formação profissional e sua alta cultura e erudição como sinais de que os professores de Goiás já poderiam participar de debates de nível nacional. Os concursos públicos para o magistério, contudo, alcançavam somente escolas da cidade-capital permitindo-se que, nas cidades interioranas, permanecesse a contratação de docentes leigos e/ou por indicação dos mandatários políticos 
locais. Sob a alegação da falta de recursos financeiros, as escolas isoladas da capital e todas as escolas do interior não tiveram professores com formação específica e tampouco pessoal selecionado por concurso. Ou seja, os mestres leigos precisavam ser substituídos, não em toda a extensão regional, mas somente nas escolas que se tornariam visíveis aos olhos da nação.

A política orçamentária que privilegiou Goiânia atingia, sobretudo, o interior do estado, inclusive no que diz respeito à construção e instalação de escolas. No caso da Diretoria de Instrução Pública, o montante de recursos a ela destinados sofreu redução significativa a partir de 1939, mas a análise dos orçamentos estaduais no período revela que as escolas de Goiânia não foram atingidas pelos cortes. Ao contrário, elas tinham previsão de orçamento individualizado e seus professores e professoras recebiam salários maiores que aqueles pagos aos docentes do interior. O governo estadual contou com o apoio dos municípios para expandir a rede de escolas primárias e com a Igreja Católica para a expansão do ensino secundário. Ludovico geralmente comparecia à inauguração dos prédios escolares construídos - ora pelos municípios, ora pela Igreja, ora ainda pela parceria entre estes dois agentes - e procurava explicitar a lógica que guiava a política orçamentária estadual:

A construção de Goiânia absorveu grande parte de nossas exíguas rendas. Era natural que se fizesse poupança em outros ramos da atividade administrativa, para que se pudesse levar avante obra de tamanho vulto para uma unidade federativa que rendia tão pouco. Os fatos vieram demonstrar [...] que estávamos cheios de razão. Goiânia seria o estímulo, a alavanca em que se apoiaram todas as nossas forças latentes para se desenvolverem. Foi o que aconteceu. Entre nós, atualmente, tudo caminha, tudo evolue, tudo progride. (Oeste, 1944, p. 1-2)

O Congresso Abeano aconteceu entre 18 de junho e $1^{\circ}$ de julho de 1942. A capital de uma região empobrecida e periférica pode exibir diante da nação a modernidade possível. A realização bem sucedida do Congresso de Educação da $\mathrm{ABE}$ e a participação de professores de Goiás no evento coroavam de êxito o esforço do governo estadual no campo educacional e, em particular, naquele operado sobre as escolas e os professores da jovem cidade-capital. Reconhecia-se que faltava ainda "[...] o melhor do aparelhamento técnico-pedagógico, capaz de integrar com propriedade as modernas exigências educacionais", conforme se pode ler no Correio Oficial (1942, p. 1), mas, não se deixava de afirmar que "uma coisa, porém, não padece dúvida: - o opulento Estado Mediterrâneo possue um apreciável quoficiente de boas escolas! - Aqui também se estuda [...]". O filho menos educado do país-pai parecia ter superado a própria condição de periferia e era aceito como parte da nação. Contudo, silenciado na história do Brasil, o surgimento de Goiânia não conquistou o lugar de projeção esperado pelos goianos, e seu papel no projeto de integração nacional não faz parte da memória da nação. A despeito disso, a nova cidade-capital consolidou-se como um sinal de mudança e uma esperança de melhores tempos para a gente goiana, conferindo materialidade a desejos e projeções fundantes da sua identidade, como confrontar as representações de Goiás como 
sertão, transformar a binterlândia em uma região moderna e civilizada e, assim, obter o reconhecimento de que o grande estado central do Brasil era essencial ao projeto da pátria rica, esclarecida e forte. Neste sentido, a busca da modernidade, o anseio pelo desaparecimento do sertão e do jequismo associado ao povo de Goiás, o desejo de pertencer e ser reconhecido como parte do ideal nacional pontuaram os discursos e justificaram as práticas, tornando singular a relação entre a escola e a cidade e entre a nação e a região.

\section{REFERÊNCIAS}

Albuquerque Jr., Durval M. de. O objeto em fuga: algumas reflexões em torno do conceito de região. Revista Fronteiras, Dourados: UFGD, v. 10, n. 17, p. 55-67, jan./ jun. 2008.

Amado, Janaína. Região, sertão, nação. Revista Estudos Históricos, Rio de Janeiro: CPDOC/FGV; Ed. FGV, v. 8, n. 15, p. 145-152, jan./jul. 1995.

Anderson, Benedict R. Comunidades imaginadas: reflexões sobre a origem e a difusão do nacionalismo. São Paulo: Companhia das Letras, 2008.

Bastos, Maria H. Câmara. Pense globalmente, pesquise localmente? Em busca de uma mediação para a escrita da história da educação. In: Mendonça, Ana Waleska C. P.; Alves, Claudia; Gondra, José G.; NAcif, Libânia; Bonato, Nailda M. da Costa (Orgs.). História da educação: desafios teóricos e empíricos. Niterói: Ed. UFF, 2007. p. 67-91.

Bolle, Willi. Grandesertão.br. São Paulo: Ed. Duas Cidades; Ed. 34, 2004.

Camargo, Alexandre de P. R. Povoar o hinterland: o ensino rural como fronteira entre estatística e educação na trajetória de Teixeira de Freitas. Revista Brasileira de História da Educação, São Paulo: SBHE; Campinas: Autores Associados, v. 10, n. 23, p. 97-132, maio/ago. 2001. Disponível em: <http://www.sbhe.org.br/novo/rbhe/RBHE23.pdf>. Acesso em: 18 jan. 2011.

Cavalcante, Maria Juraci M. Historiadores da educação no Ceará: uma experiência de formação de pesquisadores. In: Mendonça, Ana Waleska C. P.; Alves, Claudia; Gondra, José. G.; Nacif, Libânia; Bonato, Nailda. M. da Costa (Orgs.). História da educação: desafios teóricos e empíricos. Niterói: Ed. UFF, 2007. p. 93-102.

Congresso Brasileiro de Educação, 8., 1942, Goiânia. Anais... Rio de Janeiro: IBGE, 1944.

Correio Oficial do Estado de Goiaz, Goiânia: Gráfica Oficial do Estado, 1837-1943.

Cunha, Euclides da. Os sertôes. 26. ed. Rio de Janeiro: Francisco Alves, 1963.

. Diário de uma expedição. In: Galvão, Walnice N. (Org.). Euclides da Cunha (1866-1909). São Paulo: Ática, 1984. p. 85-91.

Cunha, Luiz Alexandre G. Sobre o conceito de região. Revista de História Regional, Ponta Grossa: Departamento de História da UEPG, v. 5, n. 2, p. 39-56, 2000. 
Faria Filho, Luciano M. de. História da educação e história regional: experiências, dúvidas, perspectivas. In: Mendonça, Ana Waleska C. P.; Alves, Claudia; Gondra, José G.; Nacif, Libânia; Bonato, Nailda M. da Costa (Orgs.). História da educação: desafios teóricos e empíricos. Niterói: Ed. UFF, 2007. p. 57-66.

Ferreira, Aurélio B. de Hollanda. Novo dicionário da língua portuguesa. 2. ed. Rio de Janeiro: Ed. Nova Fronteira, 1986.

Freitas, Marcos C. de. Pensamento social, ciências e imagens do Brasil: tradições revisitadas pelos educadores brasileiros. Revista Brasileira de Educação, Rio de Janeiro: ANPEd; Campinas: Autores Associados, n. 15, p. 41-61, set./dez. 2000.

Ginzburg, Carlo. O queijo e os vermes: o cotidiano e as ideias de um moleiro perseguido pela Inquisição. São Paulo: Cia. das Letras, 1987.

Gondra, José (Org.). Pesquisa em história da educação no Brasil. Rio de Janeiro: DP\&A, 2005.

Hobsbawn, Eric; Ranger, Terence. A invenção das tradiçôes. Rio de Janeiro: Paz e Terra, 1984.

Lambert, Jacques. Os dois brasis. 7. ed. São Paulo: Nacional, 1971.

Le Goff, Jacques. História e memória. Campinas: Ed. da UNICAMP, 2003.

Lima, Nísia T. Um sertão chamado Brasil: intelectuais e representação geográfica da identidade nacional. Rio de Janeiro: Revan; IUPERJ/UCAM, 1999.

Mattos, Illmar R. de. O tempo saquarema. 5. ed. São Paulo: Hucitec, 2004.

Nunes, Clarice. Caminhos da historiografia da educação: algumas reflexões. In: Mendonça, Ana Waleska C. P.; Alves, Claudia; Gondra, José G.; NAcif, Libânia; Bonato, Nailda M. da Costa (Orgs.). História da educação: desafios teóricos e empíricos. Niterói: Ed. UFF, 2007. p. 41-50.

OESTE, Goiânia: Gráfica Oficial do Estado, 1942-1945.

Oliveira, Lúcia Lippi de. A conquista do espaço: sertão e fronteira no pensamento brasileiro. Revista História, Ciências, Saúde - Manguinhos, Rio de Janeiro: FIOCRUZ; Ed. FioCruz, v. V, p. 195-215, jul. 1998.

Oliveira Viana, Francisco J. de. Instituições politicas brasileiras (1885-1951). Brasília: Conselho Editorial do Senado Federal, 1999. (Coleção Biblioteca básica brasileira).

O POPULAR, Goiânia: Gráfica O Popular, 1939.

Prado, Adonia A. Ruralismo pedagógico no Brasil do Estado Novo. Revista Estudos, Sociedade e Agricultura, Rio de Janeiro: UFRJ, n. 4, p. 5-27, jul. 1995.

Revel,Jacques. Jogos de escalas: a experiência da microanálise. Rio de Janeiro: Ed. FGV, 1998.

REVISTA DE EDUCAÇÃO do Estado de Goiás, Goiânia: Gráfica Oficial do Estado, 1938-1961.

Ricardo, Cassiano. Marcha para o Oeste. Rio de Janeiro/RJ: José Olympio, 1940. 
SAndes, Noé F. Memória, nação e região: a identidade em questão. In: Chaul, Nasr F.; Ribeiro, Paulo R. (Orgs.). Goiás, identidade, paisagem, tradição. Goiânia: Ed. UCG, 2001. p. 18-23.

SEnA, Custódia S. Interpretações dualísticas do Brasil. Goiânia: Editora UFG, 2003. Inventando regiões. Goiânia, 2009. Mimeografado.

Sevcenko, Nicolau. Literatura como missão: tensões sociais e criação cultural na Primeira República. São Paulo: Cia. das Letras, 2003.

Souza, Rosa Fátima de. Por uma teoria e uma história da escola primária no Brasil: investigações comparadas sobre a escola graduada (1870-1950). Projeto de pesquisa, 2007. Mimeografado.

Teixeira, Pedro L. Memórias. Goiânia: Ed. Cultura Goiana, 1973.

Vidal e Souza, Candice. A pátria geográfica: sertão e litoral no pensamento social brasileiro. Goiânia: Ed. UFG, 1997.

Batismo cultural de Goiânia: um ritual da nacionalidade em tempos de Marcha para o Oeste. In: Botelho, Tarcísio R. (Org.). Goiânia: cidade pensada. Goiânia/GO: Ed. UFG, 2002. p. 71-102.

White, Hayden. Trópicos do discurso: ensaios sobre a crítica da cultura. São Paulo: Edusp, 1994.

\section{SOBRE A AUTORA}

Rubia-Mar Nunes Pinto é doutora em educação pela Universidade Federal Fluminense (UFF). Professora da Universidade Federal de Goiás (UFG). E-mail: rubia-marp@bol.com.br 


\section{RUBIA-MAR NUNES PINTO}

Nação, região, sertão e a invenção dos brasis: chaves de leitura para a história da educação

Voltando-se para a invenção discursiva do Brasil, o artigo aborda a interpretação do país como nação cindida por uma dualidade e alinha representações do sertão no pensamento social brasileiro como chaves de leitura possíveis para pesquisar a história da educação nacional. Na expectativa de dar a ver um momento ímpar dos efeitos da interpretação dualística do Brasil na construção do estado de Goiás como região moderna e integrada à nação, o texto apresenta também aspectos dos preparativos para a realização do VIII Congresso Brasileiro de Educação (1942) em Goiânia/Goiás. A referência teórica advém de estudos empenhados em compreender a construção da interpretação do Brasil como cisão e a refazer os sertôes imaginados por certa elite intelectual brasileira.

Palavras-chave: nação; região; história da educação em Goiás.

Nation, region, sertão and the invention of brazils: reading keys for the history of education

Turning to the discursive invention of Brazil, the article addresses the interpretation of the country as a nation divided by a duality and aligns representations of Sertão in the Brazilian social thought as possible reading keys to research the history of national education. Aiming to highlight a unique moment of the effects of the dualistic interpretation of Brazil in the building of Goiás state as a modern region integrated to the nation, the text also presents aspects of the preparations for holding the 8th Brazilian Congress on Education (1942) in Goiânia - Goias. The theoretical framework results from studies aimed at understanding the construction of the interpretation of Brazil as a division and to rebuild the sertöes imagined by a certain Brazilian intellectual elite.

Keywords: nation; region; history of education in Goiás. 


\section{Nación, región, sertão y la invención de los brasiles: claves de lectura para la historia de la educación}

Al mirar hacia la invención discursiva de Brasil, el artículo aborda la interpretación del país como nación separada por una dualidad y vincula representaciones del sertão en el pensamiento social brasileño como posibles claves de lectura para investigar la historia de la educación nacional. En la expectativa de encontrarse a un momento impar de los efectos de la interpretación dualística de Brasil en la construcción del estado de Goiás como región moderna e integrada a la nación, el texto presenta también aspectos de los preparativos para la realización del VIII Congreso Brasileño de Educación (1942) en Goiânia/Goiás. La referencia teórica adviene de estudios empeñados en comprender la construcción de la interpretación de Brasil como dividido y a rehacer los sertôes imaginados por cierta élite intelectual brasileña.

Palabras clave: región; nación; historia de la educación en Goiás. 